\title{
Capture Efficiencies of Two Hook Types and Associated Injury and Mortality of Juvenile Muskellunge Angled with Live Baitfish
}

\author{
Kenneth G. Ostrand* ${ }^{1}$ and Michael J. SiepKer ${ }^{2}$ \\ Illinois Natural History Survey, Center for Aquatic Ecology and Conservation, Sam Parr Biological Station, \\ 6401 Meacham Road, Kinmundy, Illinois 62854, USA; and \\ Department of Natural Resources and Environmental Sciences, \\ W-503 Turner Hall, University of Illinois, Urbana, Illinois 61801, USA

\section{Steven J. CoOKe} \\ Institute of Environmental Science and Department of Biology, Carleton University, 1125 Colonel By Drive, \\ Ottawa, Ontario K1S 5B6, Canada
}

\begin{abstract}
Strict harvest regulations and a strong catchand-release ethic among recreational anglers of muskellunge Esox masquinongy have led to interest in developing strategies for reducing injury and mortality of released fish. With many anglers using live baitfish to capture muskellunge, the use of circle hooks may reduce deep hooking and hence mortality. We contrasted the performance of circle hooks and J-style aberdeen hooks when capturing juvenile muskellunge with actively fished live baitfish. The J hooks performed better than circle hooks in terms of capture efficiency. The $\mathrm{J}$ hooks were more efficient at hooking muskellunge than were circle hooks, but landing efficiency was similar between the two types. Interestingly, injury was judged to be low regardless of hook type. Neither anatomical hooking location nor hooking depth differed significantly between fish captured on $\mathrm{J}$ and circle hooks. No fish were hooked in potentially lethal locations (e.g., gullet or eye) during the use of either hook type. Ease of hook removal did not differ between hook types, and hooks were generally categorized as easy to remove. Bleeding was considered minor and did not differ between hooks. We observed no initial or delayed mortality for fish captured on J or circle hooks. Given that J hooks have a higher muskellunge capture efficiency and that the use of circle hooks did not provide any compelling conservation benefits, anglers will probably continue to use $\mathrm{J}$ hooks and avoid circle hooks. Nonetheless, use of circle hooks could be advantageous for other fishing styles (e.g., still fishing, where baitfish are often swallowed), other species, or different sizes of muskellunge.
\end{abstract}

Muskellunge Esox masquinongy fisheries are typically managed aggressively through a combination of stocking (Wahl 1999; Kerr and Lasenby 2001) and harvest regulations (Margenau and AveLallemant

\footnotetext{
* Corresponding author: kenneth_ostrand@fws.gov

${ }^{1}$ Present address: U.S. Fish and Wildlife Service, Abernathy Fish Technology Center, 1440 Abernathy Creek Road, Longview, Washington 98632, USA.

2 Present address: Missouri Department of Conservation, 551 Joe Jones Boulevard, West Plains, Missouri 65775, USA.
}

Received March 15, 2005; accepted January 23, 2006 Published online July 31, 2006
2000; Fayram 2003) because they are a popular North American recreational fish among specialized anglers (Simonson and Hewett 1999; Margenau and Petchenik 2004). In addition to traditionally low creel limits, recent muskellunge regulations have incorporated minimum length limits (Cornelius and Margenau 1999). Overall, muskellunge release rates are high as a result of harvest regulations and a strong catch-andrelease ethic among muskellunge anglers (Dent 1986; Richards and Ramsell 1986). Consequently, there are many opportunities for multiple recaptures of muskellunge by anglers before the fish reach harvestable sizes, especially considering their long life spans (Casselman et al. 1999). Collectively, these factors can lead to fish being captured and released many times, which makes high postrelease survival a necessity if these regulations are to succeed and voluntary catch and release is to be effective.

At the population level, it has been demonstrated that declines in esocid fisheries can occur even when harvest rates are low, which suggests that postrelease mortality may occur (Newman and Storck 1986). At the individual level, several catch-and-release studies have concluded that muskellunge experience stress (Miles et al. 1974; Beggs et al. 1980) and physical injury that can lead to mortality (Gasbarino 1986). Although catch-and-release mortality and sublethal effects are contentious topics in most recreational fisheries (Cooke and Suski 2005), they are still important to examine, particularly for long-lived species (Schroeder and Love 2002) such as muskellunge. As muskellunge recreational fisheries grow in popularity, fishery managers are increasingly concerned about the sustainability of catch-and-release fisheries. Most muskellunge anglers also recognize that catch-and-release mortality is a concern (Margenau and Petchenik 2004)

In most species, use of live bait is generally regarded as being more injurious and more likely to induce 


\section{J \\ (6) \\ Hook \\ Circle Hook}

FIGURE 1.- Illustrations of $\mathrm{J}$ and circle hooks used to experimentally determine muskellunge capture efficiency, hooking injury, and mortality. The $\mathrm{J}$ hooks have a hook point that is parallel to the shank, whereas circle hooks have a hook point that is more perpendicular to the shank.

mortality than is use of artificial lures (Muoneke and Childress 1994; Cooke and Suski 2005). Although specialized muskellunge anglers tend to prefer fishing with artificial lures (Margenau and Petchenik 2004), use of live baitfish with a single hook is still popular among both specialized and general anglers (Margenau and Petchenik 2004), despite the fact that mortality rates in the related esocid, northern pike E. lucius, are high with single baited-hook use (Dubois et al. 1994). To reduce injury and mortality, anglers have adapted such angling practices as keeping muskellunge in the water during release (Gasbarino 1986; Newman and Storck 1986), setting the hook immediately after a strike (Gasbarino 1986; Margenau and Petchenik 2004), and using nontraditional gear such as circle hooks (Margenau and Petchenik 2004).

Circle hooks differ from conventional J hooks in that the point of the hook is perpendicular rather than parallel to the shank of the hook (Cooke and Suski 2004). Circle hooks have been used extensively in marine fisheries to reduce both injury and mortality, but in most freshwater angling scenarios their performance varies extensively among species and among fishing techniques (Cooke and Suski 2004). Accordingly, there has been a hesitation to promote circle hook use in other fisheries, such as muskellunge fisheries, even though they may be an important conservation and management tool. Few muskellunge anglers have used circle hooks; however, many anglers would support circle hook use, and the rest would reserve judgment until after they tried the hooks (Margenau and Petchenik 2004).

Here we present findings from a study that contrasted the capture efficiency, injury level, and mortality of juvenile muskellunge captured with live baitfish on either conventional J hooks or circle hooks. We evaluate the prediction that circle hooks will result in lower injury and mortality than J hooks, as has been shown in many previous studies of predatory fishes (Cooke and Suski 2004).

\section{Methods}

The experiment was conducted in 0.14-ha, clay-lined experimental ponds at the Sam Parr Biological Station, Kinmundy, Illinois. Muskellunge were stocked in ponds 12 months before experimental angling. The ponds supported sparse aquatic vegetation and had populations of small $(\leq 120 \mathrm{~mm}$ total length [TL]) bluegills Lepomis macrochirus, naturally colonized invertebrates, and fathead minnow Pimephales promelas that were stocked monthly (3,750 minnow/ha).

Angling for muskellunge (mean TL $\pm \mathrm{SE}=413 \pm$ $7 \mathrm{~mm}$; mean weight $\pm \mathrm{SE}=343 \pm 21 \mathrm{~g}$ ) was conducted from June 1 to July 10, 2003, when surface water temperatures ranged from $21^{\circ} \mathrm{C}$ to $23^{\circ} \mathrm{C}$. All anglers fished from shore with standard gear typified by medium action rods equipped with 10 -lb test line. We used commercially available circle hooks (size 4, Demon curved-in point, fine wire, model 39952BL; Mustad \& Son, Inc.) and J-style aberdeen hooks (size 4, plain shank, ringed eye, Model 202F-4; Eagle Claw, Inc.) (see Figure 1). These sizes were chosen to keep hook gape (distance from point to shank) equal. Anglers used one of the two hook types that were baited with two fathead minnow (range $=40-55 \mathrm{~mm}$ TL) hooked through the lip; this configuration usually resulted in a corkscrew action when retrieved. Anglers were instructed to let the bait sink momentarily after casting before slowly retrieving the rig. This method was deemed best at obtaining strikes from muskellunge and differed from some muskellunge fishing strategies that involve waiting for fish to first swallow the bait. When a strike was detected, anglers using $\mathrm{J}$ hooks immediately set the hook, whereas those using circle hooks applied constant tension to the line and continued to reel until landing the fish. Unlike conventional hooks (i.e., J hooks), circle hooks perform optimally when gentle pressure is applied rather than a strong, quick hook set (Cooke and Suski 2004). Anglers rotated rods at $1-\mathrm{h}$ intervals to ensure that all anglers used different hook types.

When a muskellunge struck at the baited hook, the angler attempted to hook the fish and recorded the number of missed and hooked muskellunge (proportion hooked was hooking efficiency). If the fish was hooked, the angler recorded whether the fish was successfully landed or not (proportion landed was 


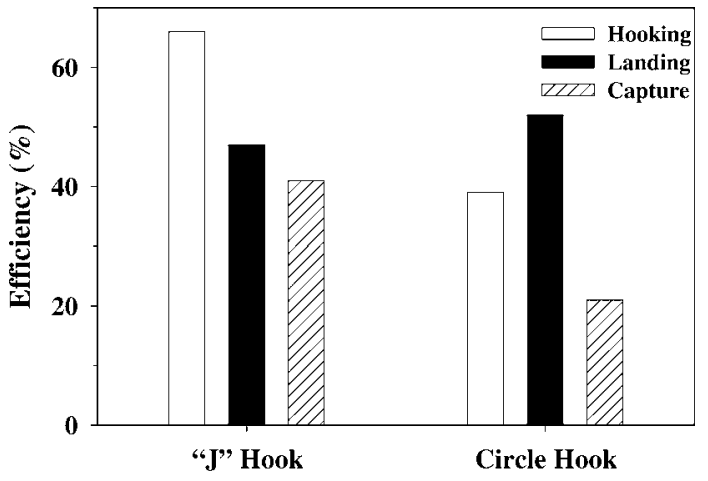

Figure 2.-Percentages of hooked, landed, and captured juvenile muskellunge angled with $\mathrm{J}$ or circle hooks.

landing efficiency). We used percent capture efficiency to assess hook performance. The capture efficiency function form is

$$
\mathrm{CE}=(L / S) \times 100,
$$

where $\mathrm{CE}=$ capture efficiency, $L=$ number of muskellunge landed on each hook type, and $S=$ number of muskellunge that struck at each hook type. Higher relative capture efficiency values indicated that a particular hook was performing better. Angler ability, patchiness of fish, and recapture rates were not considered to be significant variables because all anglers had intermediate levels of fishing experience and because fish were sufficiently abundant (Dunmall et al. 2001).

If a fish was landed, the angler then assessed injury level from data collected on three categories: (1) anatomical hooking location, (2) ease of hook removal, and (3) degree of bleeding. The angler recorded the anatomical location of the hook (upper jaw, lower jaw, side jaw, roof of mouth, eye, or gullet) as well as hooking depth. Hooking depth was measured from the anterior aspect of the lower lip to the most posterior point of hook penetration. To enable comparison of hooking depth among fish of different sizes, the TL of the fish was divided by the hooking depth (Dunmall et al. 2001; Cooke et al. 2003a). The angler then removed the hook and recorded the ease of hook removal. Hook removal was categorized as (1) easy (the hook could be removed by hand without the use of hemostats); (2) hard (hook removal required hemostats but did not cause substantial injury); and (3) impossible (the hook could not be removed without causing substantial injury) (Cooke et al. 2001). If hook removal was deemed impossible, the line was cut. The presence or absence of bleeding was recorded. If blood was present, the angler visually assessed the bleeding and judged if it was severe (excessive bleeding) or minor (minimal traces of blood).

From these data, injury was then judged to be either minor or severe. Injury was considered minor if the fish had no or minor bleeding, had easy or hard hook removal, and was hooked in the upper, lower, or side jaw or the roof of the mouth. Injury was considered severe for fish hooked in the upper, lower, or side jaw or roof of the mouth if the fish was deemed as having severe bleeding, regardless of the ease of hook removal. Injury for these fish was also considered severe if they were categorized as having impossible hook removal, regardless of the amount of bleeding. Fish that were hooked in the gullet or eye were considered to have severe injury, regardless of the amount of bleeding or ease of hook removal. Fish were measured for TL (mm) and released.

All captured muskellunge were monitored for mortality. Initial mortality was determined by immediate observations of hooking in vital areas, excessive bleeding, loss of gill color, lack of respiration, or inability of fish to volitionally maintain equilibrium and swim after release. Delayed mortality was determined by visually inspecting ponds for expired fish $24 \mathrm{~h}$ after angling from June 2 to July 11, 2003.

We used a $t$-test to determine the difference between the hooking depth of fish angled with $\mathrm{J}$ and circle hooks (Sokal and Rohlf 1981). We used chi-square tests for goodness of fit to compare categorical variables (i.e., hooking efficiency, landing efficiency, anatomical hooking locations, ease of hook removal, and presence and absence of bleeding) between $\mathrm{J}$ and circle hooks (Sokal and Rohlf 1981). All statistical tests employed a significance level $\alpha$ of 0.05 , and mean values are presented with SEs.

\section{Results}

$\mathrm{J}$ hooks performed better than circle hooks when angling juvenile muskellunge (Figure 2). In total, 27 muskellunge struck at baited J hooks and 58 struck at baited circle hooks. J hooks had greater hooking efficiency (chi-square $=5.38, \mathrm{df}=1, P<0.05$ ) than circle hooks. Of the fish $(N=18)$ that struck at J hooks, $66 \%$ were hooked; only $39 \%$ of the fish that struck at circle hooks $(N=23)$ were hooked. Landing efficiency (chi-square $=0.32, \mathrm{df}=1, P=0.56$ ) was similar for $\mathrm{J}$ hooks $(47 \%, N=11)$ and circle hooks $(52 \%, N=12)$. Capture efficiency (chi-square $=3.75$, df $=1, P<$ 0.05 ) was greater for muskellunge captured on J hooks (41\%) than for those caught on circle hooks $(21 \%)$.

Injuries seldom occurred, but those that did were considered minor for muskellunge captured on either $\mathrm{J}$ or circle hooks. Anatomical hooking location did not differ significantly $($ chi-square $=4.45, \mathrm{df}=3, P=0.21$ ) 


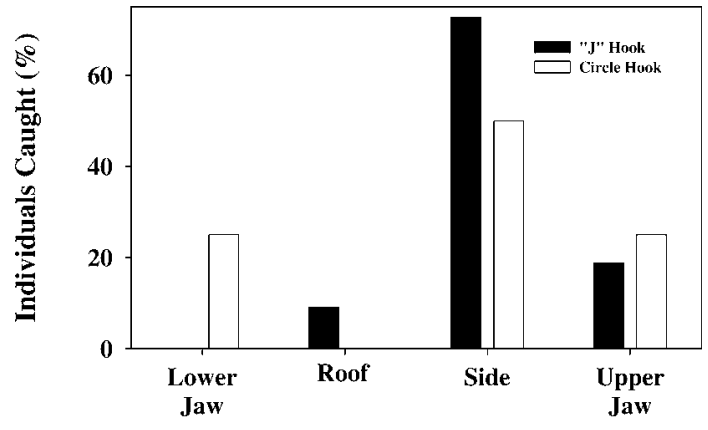

Anatomical Hooking Location

FIGURE 3.-Anatomical hooking locations for juvenile muskellunge captured with $\mathrm{J}$ or circle hooks, expressed as a percentage of the total number of individuals caught on each hook type.

by hook type (Figure 3). Overall, muskellunge were hooked most frequently in the side of the jaw (61\%), followed by the upper jaw (22\%) and lower jaw (13\%). Very few fish were hooked in the roof of the mouth (4\%). None of the fish were hooked in the gullet $(0 \%)$ or eye $(0 \%)$. Hooking depth did not differ $(t=1.44$, df $=20, P=0.17$ ) among fish captured with $\mathrm{J}$ hooks (mean hooking depth : TL ratio $=0.08 \pm 0.01$ ) or with circle hooks (mean $=0.06 \pm 0.01$ ). Ease of hook removal did not vary between hook types (chi-square $=$ 1.01 , df $=1, P=0.31$, and most hookings were deemed easy to remove (J, 90\%; circle, $75 \%$ ). All the remaining fish were deemed as having hard-to-remove hooks; none of the landed muskellunge had hooks that were impossible to remove. Because of shallow hooking, the presence of blood was uniformly minor for both $\mathrm{J}$ ( $27 \%$ of the total) and circle (13\% of the total) hook types (chi-square $=1.05, \mathrm{df}=1, P=0.30$ ). None of the hooking wounds for either hook type was judged to be bleeding severely.

We observed no initial mortality for juvenile muskellunge captured on either J or circle hooks. In addition, no delayed mortalities were observed after their release or throughout the duration of the study.

\section{Discussion}

Hook style influenced the efficiency of juvenile muskellunge capture. In our study, more fish were hooked and successfully landed by use of $\mathrm{J}$ hooks than circle hooks. Although circle hooks were less efficient, we observed more than twice as many strikes for circle hooks than for $\mathrm{J}$ hooks. Circle hooks may produce a different retrieval presentation than $\mathrm{J}$ hooks; however, additional experiments will be required to test whether foraging behavior differs as a result of hook configu- ration. Even so, our results are consistent with other reports that suggest greater capture efficiencies with $\mathrm{J}$ hooks for red drum Sciaenops ocellatus (Aguilar et al. 2002), striped bass Morone saxatilis (Lukacovic 2000), largemouth bass Micropterus salmoides (Cooke et al. 2003b), and walleyes Sander vitreus (Jones 2005). Collectively, these results and those of our study indicate that capture efficiency is generally lower when circle hooks are used.

Differences in injury rates between $\mathrm{J}$ and circle hooks are of concern for specialized freshwater fisheries, such as muskellunge fisheries, primarily because of the use of live bait rigs designed to be swallowed by trophy fish (Gasbarino 1986). This tendency exacerbates concerns for live release, because J hooks tend to cause more tissue damage and bleeding than circle hooks when ingested deeply (McNair 1997; Skomal et al. 2002). However, the majority of previous studies (Cooke and Suski 2004) examining differences between circle and $\mathrm{J}$ hooks have been conducted on species that primarily employ inertial suction feeding (Webb 1984).

In our study, J hooks did not cause more injury or bleeding than circle hooks. The shallow hooking depth, lack of injury, and bleeding may be reflective of muskellunge foraging behavior and mouth morphology. Esocid foraging behavior is typified by active lunging or grasping at prey as opposed to relying solely on expansion of the mouth to rapidly create negative pressure in the buccal cavity (Webb and Skadsen 1980; New et al. 2001); this behavior potentially reduces the risk of deep hooking and bleeding. In our study, muskellunge were more often hooked in the corner of the mouth, upper jaw, or lower jaw and exhibited minimal bleeding regardless of gear configuration, presumably because of their foraging behavior. Indeed, fish that rely on inertial suction feeding, such as largemouth bass, have greater hooking depths, higher injury rates, and higher mortality (Cooke et al. 2003b). However, muskellunge may experience a different outcome if anglers use a different fishing style or strategy.

Angling techniques that allow fish to swallow bait rigs may result in severe and ultimately fatal wounds. In our study, anglers were instructed to set the hook or begin retrieving line immediately after a strike was detected. As a result, we observed very few fish $(<0 \%)$ hooked in areas that were considered to be potentially lethal (e.g., gullet, eye). Esocids in our ponds, like those of Lawler (1964) and Weithman and Anderson (1978), were resilient to angling. In fact, we observed no initial mortality during our study. Indeed, even those that exhibited bleeding survived upon release, regardless of hook type. Similarly, we observed no 
delayed mortality associated with the use of either hook type; however, our methods may have underestimated delayed mortality because we were able to enumerate only those individuals that were observable from the bank and that were not consumed by scavengers. Anecdotal reports in some outdoor media and angling websites suggest that before applying pressure, anglers must allow ample time for circle hooks to be swallowed. This angling strategy is substantially different from our approach. We argue that under no circumstances should fish be provided with time to swallow the hook, because this can only increase the chances of hooking in potentially lethal areas. However, if anglers adopt this angling strategy, we surmise that circle hooks would probably impart some advantages over $\mathrm{J}$ hooks when bait rigs are swallowed, according to the body of work done on other species (Cooke and Suski 2004). Clearly, the benefits of circle hooks are not ubiquitous across all fish species or angling methods; in some cases, particularly for muskellunge fisheries, they may provide little conservation benefit over conventional gear if bait is fished actively.

Although a high number of anglers endorse voluntary live release, the loss of muskellunge from a population either by harvest or catch-and-release mortality may affect a fishery's trophy potential (Margenau and Petchenik 2004). Even though larger esocids, specifically trophy fish, may be at risk because of angling-associated exhaustion and sublethal stress (Miles et al. 1974; Beggs et al. 1980), smaller fish may be less prone to these negative consequences when bait is actively fished. Our results suggest the incidental bycatch of small muskellunge that may occur in some fisheries will probably result in null or inconsequential effects on a fishery if anglers employ strategies whereby baitfish are not swallowed by muskellunge before the hook is set. However, future research will be needed on a range of muskellunge sizes, including trophy sizes, to examine the role that various gear types, angling techniques, and cumulative effects of multiple captures have on muskellunge populations.

\section{Acknowledgments}

The study benefited from the assistance of B. J. Bauer, L. Csoboth, P. Beck, N. Siepker, and J. Robertson of the Sam Parr Biological Station. The Illinois Natural History Survey and the University of Illinois provided financial assistance for this study.

\section{References}

Aguilar, R., P. S. Rand, and G. H. Beckwith, Jr.. 2002. Quantifying the catch-and-release mortality rate of adult red drum in the Neuse River Estuary. North Carolina
Fisheries Resource Grant Program, Final Report 01-FEG07, Raleigh.

Beggs, G. L., G. F. Holeton, and E. J. Crossman. 1980. Some physiological consequences of angling stress in muskellunge, Esox masquinongy Mitchill. Journal of Fish Biology 17:649-659.

Casselman, J. M., C. J. Robinson, and E. J. Crossman. 1999. Growth and ultimate length of muskellunge from Ontario water bodies. North American Journal of Fisheries Management 19:271-290.

Cooke, S. J., D. P. Philipp, K. M. Dunmall, and J. F. Schreer. 2001. The influence of terminal tackle on injury, handling time, and cardiac disturbance of rock bass. North American Journal of Fisheries Management 21:333-342.

Cooke, S. J., B. L. Barthel, and C. D. Suski. 2003a. Effects of hook type on injury and capture efficiency of rock bass, Ambloplites rupestris, angled in southeastern Ontario. Fisheries Management and Ecology 10:269-271.

Cooke, S. J., C. D. Suski, M. J. Siepker, and K. G. Ostrand. 2003b. Injury rates, hooking efficiency, and mortality potential of largemouth bass (Micropterus salmoides) captured on circle hooks and octopus hooks. Fisheries Research 61:135-144.

Cooke, S. J., and C. D. Suski. 2004. Are circle hooks an effective tool for conserving marine and freshwater recreational catch-and-release fisheries? Aquatic Conservation: Marine and Freshwater Ecosystems 14:299-326.

Cooke, S. J., and C. D. Suski. 2005. Do we need speciesspecific guidelines for catch-and-release recreational angling to effectively conserve diversity fishery resources? Biodiversity and Conservation 14:1195-1209.

Cornelius, R. R., and T. L. Margenau. 1999. Effects of length limits on muskellunge in Bone Lake, Wisconsin. North American Journal of Fisheries Management 19:300-308.

Dent, R. J. Jr. 1986. A case history of voluntary catch and release of muskellunge with management implications for fishery programs. American Fisheries Society, Special Publication 15, Bethesda, Maryland.

Dubois, R. B., T. L. Margenau, R. S. Stewart, P. K. Cunningham, and P. W. Rasmussen. 1994. Hooking mortality of northern pike angled through ice. North American Journal of Fisheries Management 14:769-775.

Dunmall, K. M., S. J. Cooke, J. F. Scheer, and R. S. McKinley. 2001. The effect of scented lures on the hooking injury and mortality of smallmouth bass caught by novice and experienced anglers. North American Journal of Fisheries Management 12:242-248.

Fayram, A. H. 2003. A comparison of regulatory and voluntary release of muskellunge and walleyes in northern Wisconsin. North American Journal of Fisheries Management 23:619-624.

Gasbarino, P. L. 1986. Catch and release of muskellunge philosophy and methods. American Fisheries Society, Special Publication 15, Bethesda, Maryland.

Jones, T. S. 2005. The influence of circle hooks on the capture efficiency and injury of walleyes. North American Journal of Fisheries Management 25:725-731.

Kerr, S. J., and T. A. Lasenby. 2001. Esocid stocking: an annotated bibliography and literature review. Ontario Ministry of Natural Resources, Fish and Wildlife Branch, Peterborough. 
Lawler, G. H. 1964. Further evidence of hardiness of "silver" pike. Journal of the Fisheries Research Board of Canada 21:651-652.

Lukacovic, R. 2000. Hooking mortality of deep and shallow hooked striped bass under different environmental conditions in Chesapeake Bay. In D. R. Weinrich, P. G. Piavis, B. H. Pyle, A. A. Jarzynski, J. C. Walstrum, R. A. Sadzinski, E. J. Webb, H. W. Rickabaugh, E. Zlokovitz, L. P. Mower, R. Lukacovic, and K. A. Whiteford, editors. Stock assessment of selected resident and migratory recreational finfish species within Maryland's Chesapeake Bay. Maryland Department of Natural Resources, Federal Aid in Sport Fish Restoration, Project F-54-R, Annual Report, Baltimore.

Margenau, T. L., and J. B. Petchenik. 2004. Social aspects of muskellunge management in Wisconsin. North American Journal of Fisheries Management 24:82-93.

Margenau, T. L., and S. P. AveLallemant. 2000. Effects of a 40-inch minimum length limit on muskellunge in Wisconsin. North American Journal of Fisheries Management 20:986-993.

McNair, D. 1997. Effect of gear and methods on marine sports salmon hooking mortality rates. Pacific Fisheries Management Council, NEAP Final Research Report 68.2, Portland, Oregon.

Miles, H. M., S. M. Loehner, D. T. Michaud, and S. L. Salivar. 1974. Physiological responses of hatchery reared muskellunge (Esox masquinongy) to handling. Transactions of the American Fisheries Society 103:336-342.

Muoneke, M. I., and W. M. Childress. 1994. Hooking mortality: a review for recreational fisheries. Reviews in Fisheries Science 2:123-156.

New, J. G., L. A. Fewkes, and A. N. Khan. 2001. Strike feeding behavior in the muskellunge, Esox masquinongy: contributions of lateral line and visual sensory systems. Journal of Exploratory Biology 204:1207-1221.

Newman, D. L., and T. W. Storck. 1986. Angler catch, growth, and hooking mortality of tiger muskellunge in small centrarchid-dominated impoundments. American Fisheries Society, Special Publication 15, Bethesda, Maryland.

Richards, K., and R. Ramsell. 1986. Quantifying the success of muskellunge catch and release programs: a summary of cooperative angler-tangling studies. American Fisheries Society, Special Publication 15, Bethesda, Maryland.

Schroeder, D. M., and M. S. Love. 2002. Recreational fishing and marine fish populations in California. California Cooperative Ocean Fisheries Investigations Report 43:182-190.

Simonson, T. D., and S. W. Hewett. 1999. Trends in Wisconsin's muskellunge fishery. North American Journal of Fisheries Management 19:291-299.

Skomal, G. B., B. C. Chase, and E. D. Prince. 2002. A comparison of circle hook and straight hook performance in recreational fisheries for juvenile Atlantic bluefin tuna. Pages 57-65 in J. A. Lucy and A. L. Studholme, editors. Catch and release in marine recreational fisheries. American Fisheries Society, Symposium 30, Bethesda, Maryland.

Sokal, R. R., and F. J. Rohlf. 1981. Biometry. Freeman, New York.

Wahl, D. H. 1999. An ecological context for evaluating the factors influencing muskellunge stocking success. North American Journal of Fisheries Management 19:238-248.

Webb, P. W. 1984. Body and fin form and strike tactics of four teleost predators attacking fathead minnows (Pimephales promelas) prey. Canadian Journal of Fisheries and Aquatic Sciences 41:157-165.

Webb, P. W., and J. M. Skadsen. 1980. Strike tactics of Esox. Canadian Journal of Zoology 58:1462-1469.

Weithman, S. A., and R. O. Anderson. 1978. Angling vulnerability of Esocidae. Proceedings of the Annual Conference Southeastern Association of Fish and Wildlife Agencies 30(1976):99-102. 